\title{
THE SITES OF ORIGIN OF BRAIN STEM NEUROTENSIN AND SEROTONIN PROJECTIONS TO THE RODENT NUCLEUS RAPHE MAGNUS ${ }^{1}$
}

\author{
ALVIN J. BEITZ ${ }^{2}$ \\ Department of Anatomy, University of South Carolina, Columbia, South Carolina 29208 \\ Received December 4, 1981; Revised February 22, 1982; Accepted February 22, 1982
}

\begin{abstract}
The combined horseradish peroxidase retrograde transport-peroxidase-antiperoxidase immunohistochemical procedure was utilized in the present study to ascertain the sites of origin of serotonin and neurotensin projections to the rodent nucleus raphe magnus. The major serotonin inputs to the raphe magnus arise from the B-8 and B-9 groups of Dahlstrom and Fuxe (Dahlstrom, A., and K. Fuxe (1964) Acta Physiol. Scand. Suppl. 232 62: 1-55), the nucleus reticularis paragigantocellularis, and the nucleus reticularis gigantocellularis pars $\alpha$. Neurotensinergic projections to the raphe magnus originate predominantly from the periaqueductal gray, the nucleus solitarius, the dorsal and ventral parabrachial nuclei, and the nucleus cuneiformis. The periaqueductal gray and the nucleus paragigantocellularis were found to provide both a neurotensin and a serotonin projection to this raphe nucleus. The present results indicate that several brain stem nuclei, which have been implicated previously in endogenous analgesia mechanisms, provide serotonergic and neurotensinergic input to the nucleus raphe magnus.
\end{abstract}

Reynolds (1969) and Mayer and Liebeskind (1974) were among the first investigators to demonstrate that potent analgesia could be produced by electrical brain stimulation in freely moving animals. Most of the early studies of centrally induced analgesia focused on the midbrain periaqueductal gray (PAG) from which stimulation-produced analgesia was best elicited. Subsequent studies have demonstrated that stimulation of the medullary nucleus raphe magnus (NRM), a source of serotonin neurons, also produces potent analgesia (Fields and Basbaum, 1978; Oliveras et al., 1979). Moreover, it has been shown that stimulation of the PAG alters the activity of cells in the NRM (Pomeroy and Behbehani, 1979) and that lesions of the NRM produce a pronounced decrease in nociceptive threshold (Proudfit, 1981). Both the analgesic action of opiates and electrical stimulation of the PAG are blocked by lesion of the dorsolateral part of the spinal cord (Basbaum et al., 1977). Since (1) the PAG sends very few direct projections to the spinal cord and (2) a PAG-NRM projection was demonstrated (Ruda, 1976; Gallager and Pert, 1978; Abols and Basbaum, 1981), it was proposed that the raphe-spinal pro-

\footnotetext{
' This work was supported by Grant BNS 7906486 from the National Science Foundation and, in part, by Grant I RO1 NS17401-01 from the National Institutes of Health.

${ }^{2}$ Present address: Department of Veterinary Biology, School of Veterinary Medicine, University of Minnesota, St. Paul, MN 55108.
}

jection is the critical link in the analgesia produced by PAG stimulation (Fields and Basbaum, 1978).

Although the raphe-spinal system may play a role in PAG stimulation-produced analgesia, the role of the NRM in exogenous opiate action in still far from clear. Although systemic administration of opiates has been shown by some investigators to increase the discharge rate of raphe magnus neurons (Deakin et al., 1977; Oleson et al., 1978), most investigators interpret these results as indicating that raphe neurons are activated indirectly from the PAG (Fields and Basbaum, 1978). For instance, Proudfit (1981) has demonstrated recently that raphe magnus neurons are not involved directly in mediating the antinociceptive actions of opiates. In contrast Dickenson and co-workers (1979) reported that the rodent NRM is sensitive to the microinjection of opiates and that naloxone can reverse the analgesic action of NRM stimulation.

Although some controversy exists, the majority of studies to date would suggest that opiates administered systemically do not act at the level of the raphe. It is probable that opiate compounds act at other CNS sites which, in turn, influence the NRM as indicated above. The present investigation is part of an ongoing study designed to elucidate the origin of several neurotransmitter and neuropeptide inputs to the NRM. This report deals with the brain stem origin of serotonergic and neurotensin projections to the NRM and the results are 
correlated with the known distribution of opiate receptors and with the location of brain nuclei which have been implicated as part of the endogenous analgesia system.

\section{Materials and Methods}

The combined retrograde HRP histochemical and immunocytochemical procedure developed by Bowker and co-workers (1981) was employed with slight modification in order to determine the distribution of serotonin (5$\mathrm{HT}$ )- and neurotensin (NT)-immunoreactive cell bodies which project to the NRM. Eighteen adult SpragueDawley rats were injected stereotaxically with horseradish peroxidase (HRP) by means of either iontophoretic or pressure injections. Iontophoretic injections of HRP were delivered via a glass micropipette filled with a $13 \%$ solution of HRP in $0.05 \mathrm{~m}$ Tris buffer $(\mathrm{pH} \mathrm{7.6)}$. The driving force for the microelectrophoretic injections was supplied by a $1.8-\mu \mathrm{A}$ positive current delivered by a constant current source (Midgard Electronics) at a pulse rate of $7 \mathrm{sec}$ on, $7 \mathrm{sec}$ off for a duration of 20 to $40 \mathrm{~min}$. Pressure injections (ranging from 0.1 to $2.0 \mu \mathrm{l}$ ) of a $40 \%$ solution of HRP were delivered directly from either a 1or a $10-\mu \mathrm{l}$ syringe. After 24 to $72 \mathrm{hr}$, the animals were treated with colchicine $(60 \mu \mathrm{g}$ in $6 \mu \mathrm{l}$ of $\mathrm{NaCl})$ injected intraventricularly. The animals were perfused 24 to $48 \mathrm{hr}$ later with warm physiological saline followed by $1000 \mathrm{ml}$ of cold 3.5 to $3.8 \%$ paraformaldehyde solution in $0.1 \mathrm{M}$ sodium phosphate buffer or by $1000 \mathrm{ml}$ of $3.5 \%$ paraformaldehyde, $0.1 \%$ glutaraldehyde. In either case, the fixative was followed by $1000 \mathrm{ml}$ of a phosphate-buffered sucrose solution $(30 \%)$. The brains were removed and $40-\mu \mathrm{m}$ sections were cut on a freezing microtome. Brain stem sections were subsequently incubated for $5 \mathrm{~min}$ in a $0.5 \%$ $\mathrm{CoCl}_{2}$ solution in $0.1 \mathrm{M}$ Tris buffer prior to incubation in $0.025 \%$ diaminobenzidine (DAB) containing $0.01 \% \mathrm{H}_{2} \mathrm{O}_{2}$. Incubation of tissue sections in $\mathrm{CoCl}_{2}$ prior to the $\mathrm{DAB}$ reaction yields a black reaction product in the retrogradely labeled neurons.

In some cases, the heavy metal intensification procedure of Adams (1981) was utilized in the DAB-HRP reaction instead of prior treatment of $\mathrm{CoCl}_{2}$. With this method, both nickel ammonium sulfate and cobalt chloride were added directly to the DAB solution. This method is much simpler and faster than the cobalt chloride procedure and has the added advantage of providing a more sensitive substrate for detecting HRP. One disadvantage of the heavy metal intensification procedure is that it often results in the presence of a black precipitate over the tissue section. Although some of this precipitate is lost during subsequent processing of the tissue for immunohistochemistry, it can be eliminated by bubbling nitrogen gas through the phosphate buffer that is used to make the DAB solution.

Following HRP histochemistry, the brain stem sections were rinsed in $0.1 \mathrm{~m}$ phosphate-buffered saline (PBS) and processed for immunocytochemistry utilizing the unlabeled antibody, peroxidase-antiperoxidase (PAP) method of Sternberger (1979). Serotonin antiserum was obtained from Dr. Robert Elde (Department of Anatomy, University of Minnesota) and has been characterized previously (Maley and Elde, 1982), while antiserum against NT was purchased from Immuno Nuclear Corp. (Stillwater, MN). Sections were incubated from 12 to 36 $\mathrm{hr}$ in either $5-\mathrm{HT}$ antiserum $(1: 3000$ to $1: 5000)$ or NT antiserum (1:1000) diluted in a PBS/Triton X-100 solution. After the immunocytochemical staining procedures, sections were incubated in the DAB solution without prior incubation in $\mathrm{CoCl}_{2}$ to yield a brown reaction product in immunoreactive cells. Immunocytochemical specificity was established by incubating the tissue with diluted 5-HT antisera preabsorbed with $100 \mu \mathrm{g}$ of $5-\mathrm{HT} /$ $\mathrm{ml}$ of antisera or with diluted NT antisera preabsorbed with $100 \mu \mathrm{g}$ of $\mathrm{NT} / \mathrm{ml}$ of antisera. These immunohistochemical controls were negative.

Double labeled neurons which contained either 5-HTor NT-like immunoreactivity and HRP-reactive granules were identified by the presence of both black and brown reaction product within their cytoplasm. The HRP reaction product consisted of black punctate granules which were present in the cell soma and extended into the dendritic processes (Fig. $1 A$ ). The PAP reaction product, on the other hand, appeared as a homogeneous light brown coloration which occurred throughout the cell cytoplasm, exclusive of the nucleus (Fig. 1A). Single labeled neurons were easily identified by the presence of either a black granular reaction product (HRP-labeled cell) or a brown reaction product (immunoreactive cell) throughout the neuronal cytoplasm (Fig. 1, B and $C$ ).

Small iontophoretic injections of HRP were made into the raphe magnus in two animals and the brain sections then were processed with the tetramethylbenzidine (TMB) procedure routinely used in our laboratory (Beitz, 1982). Because the TMB procedure is more sensitive than the DAB-cobalt chloride method used in the above combined retrograde transport-immunohistochemical experiments (see Mesulam and Rosene, 1979), these two cases were used to chart the total brain stem input to the NRM. In addition, control injections of the tracer enzyme were made into the nucleus reticularis gigantocellularis (NRG), the inferior olive, and the area immediately dorsal to the NRM. The brain tissue from these control cases also was processed with the TMB method and was compared to the two NRM injections. This was done to ascertain if any of the labeling that occurred in our double label experiments was due to spread of the enzyme and subsequent uptake by axonal endings outside of the NRM.

\section{Results}

\section{Description of injection sites}

Both the iontophoretic injections and the $0.2-\mu$ l pressure injections of HRP resulted in the confinement of the dense core of black reaction product to the vicinity of the NRM. The HRP deposit following injections of 1 to $2 \mu \mathrm{l}$ of the tracer enzyme typically spread outside of the region of the NRM into the adjacent nucleus reticularis gigantocellularis, the inferior olivary nucleus, or the area dorsal to NRM. Representative examples of HRP iontophoretic and pressure injection sites are shown in Figure 2. Following iontophoretic injections of HRP into the raphe magnus, only a few double labeled neurons were observed within brain stem nuclei. In contrast, pressure 

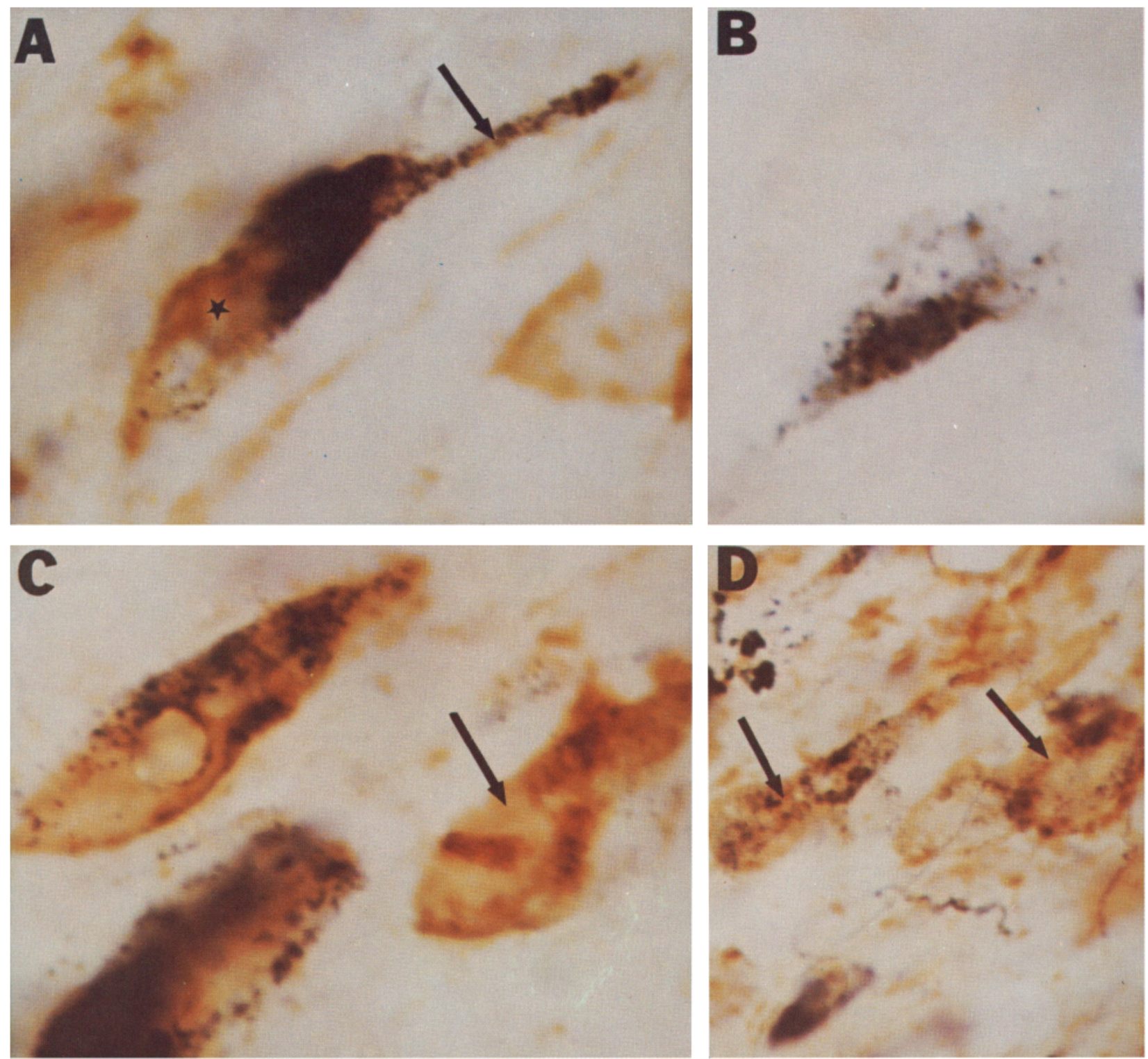

Figure 1. Vericolor photomicrographs illustrating the three types of neuronal labeling observed with the combined HRP retrograde transport-PAP immunohistochemical technique. $A$, Double labeled serotonin-like immunoreactive cell from the nucleus reticularis paragigantocellularis. The black HRP reaction product can be observed to extend out into the dendritic processes (arrow) and the brown immunohistochemical reaction product is evident in the neuronal cytoplasm (star). Magnification $\times 900$. $B$, Single HRP-labeled neuron from the ventrolateral periaqueductal gray distinguished by the presence of black granular reaction product. Magnification $\times 900$. $C$, One single labeled serotonin-like immunoreactive cell $($ arrow) and two double labeled serotonin neurons from the ventrolateral PAG. Magnification $\times 900$. $D$, Two double labeled neurotensin-like immunoreactive neurons from the midbrain periaqueductal gray (arrows). Magnification $\times 750$.

injections of the enzyme marker resulted in a marked increase in the number of double labeled neurons throughout the brain stem. Because of the increased labeling that occurred with use of pressure injections into the NRM, the results reported below are based predominantly on observations from animals receiving pressure injections of HRP. Some problems which limit the use of iontophoretic injections with the HRP retrograde transport-immunohistochemical technique are discussed below.

Sources of brain stem serotonergic input to the nucleus raphe magnus. Six brain stem areas were found to contain 5-HT double labeled cells following HRP injections into the NRM. These structures are listed in Table I together with an estimate of the relative number of double labeled cells in each. The location of double labeled 5-HT cells, as well as the distribution of single labeled HRP cells and single labeled 5-HT-immunoreactive neurons, is illustrated in Figure 3. Each 5-HT-projecting structure was identified in at least three experiments.

Rostrally, the B-7, B-8, and B-9 groups of Dahistrom and Fuxe (1964) contained the greatest number of double labeled cells. The predominant cell types which were double labeled in the B- 8 group were fusiform-shaped neurons measuring 14 to $20 \mu \mathrm{m}$ in diameter and triangular 

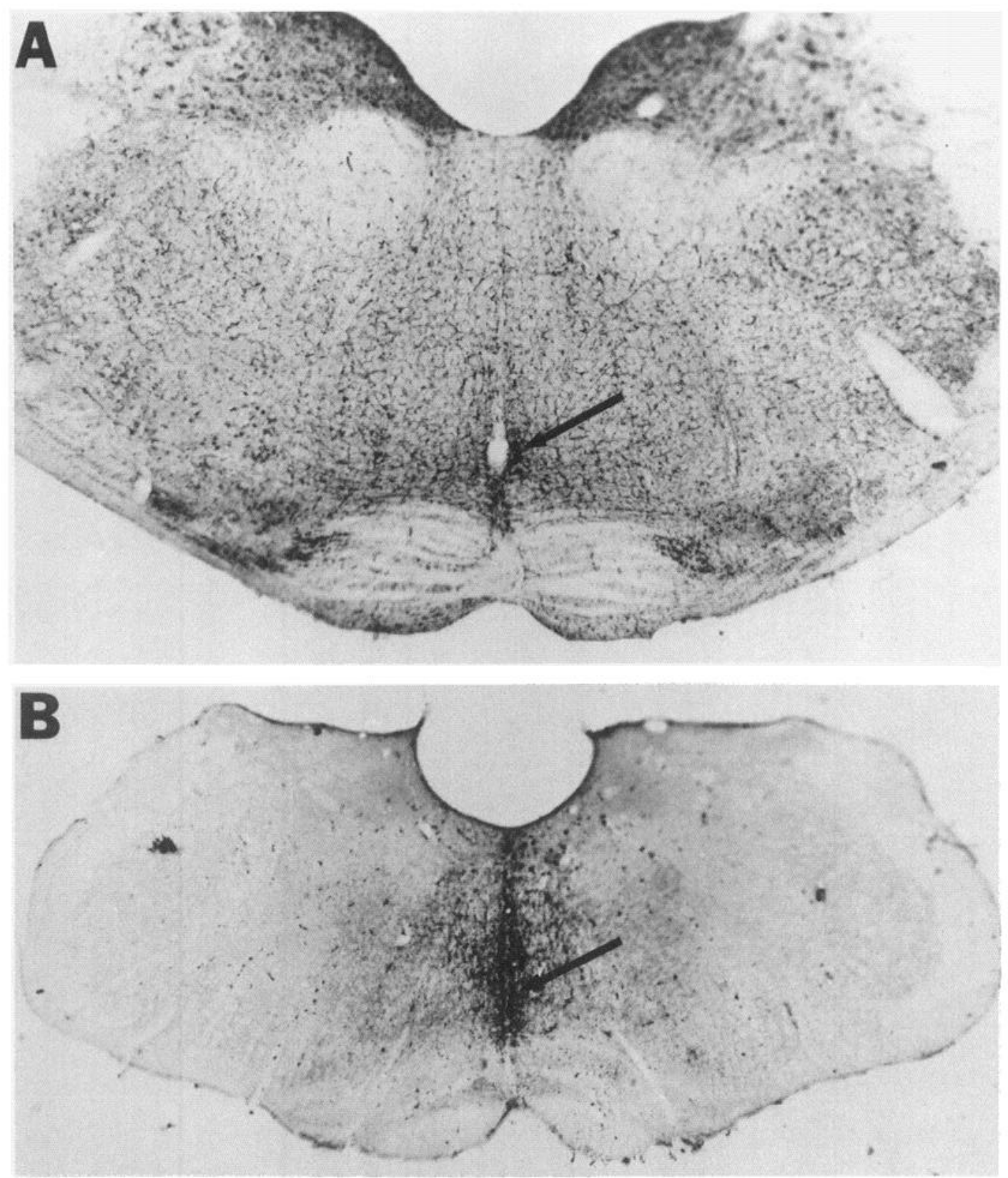

Figure 2. Examples of HRP injection sites in the nucleus raphe magnus. $A$, Coronal brain section illustrating the size of the HRP deposit from case R-251 in which an iontophoretic injection of HRP was made into the raphe magnus (arrow). $B$, Coronal section through the rostral medulla depicting the size of the injection site (arrow) from case R-381 following a pressure injection of HRP in the raphe magnus. Some spread of the enzyme tracer is evident in the area dorsal to the raphe magnus.

neurons measuring 16 to $21 \mu \mathrm{m}$ in diameter. The B-9 group also contained triangular double labeled neurons in the 16- to $21-\mu \mathrm{m}$ range. In addition, a large number of double labeled multipolar neurons, with cell diameters ranging from 18 to $25 \mu \mathrm{m}$, were evident. Within the B-7 group of Dahlstrom and Fuxe (1964), 5-HT double labeled cells were concentrated within the ventrolateral periaqueductal gray (PAG) and along the lateralmost aspect of the dorsal raphe nucleus. Cell labeling in the PAG was confined to bipolar and triangular neurons with diameters in the 13- to $19-$ and $18-$ to $24-\mu \mathrm{m}$ ranges, respectively. At lower brain stem levels, the nucleus paragigantocellularis and the nucleus gigantocellularis pars $\alpha$ both displayed fusiform-shaped and polygonal double labeled cells. The fusiform labeled cells in the former nucleus ranged in size from 15 to $23 \mu \mathrm{m}$, while in the latter nucleus, they were 22 to $29 \mu \mathrm{m}$ in diameter. Likewise, the labeled polygonal, multipolar cell variety was larger in size in the nucleus gigantocellularis pars $\alpha$.

Sources of brain stem neurotensin input to the nucleus raphe magnus. Several brain stem areas were found to contain NT double labeled neurons following HRP injections into the NRM. These structures are listed in Table I together with an estimate of the relative number of labeled cells in each area and the percentage of HRPlabeled cells which contained neurotensin in each nu- 
TARI.F I

A summary of the brain stem sources of neurotensin and serotonin inputs to the nucleus of raphe magnus

The number of double labeled cells is indicated by pluses in decreasing order (between ++++ and 0 ). The percentages of HRP cells in each nucleus which were double labeled is indicated for NT and 5-HT, respectively. This percentage represents the average percentage of HKI' cells which were double labeled from three cases.

\begin{tabular}{|c|c|c|c|c|}
\hline Nucleus & $\begin{array}{c}\text { Number of Double } \\
\text { Labeled Neurotensin } \\
\text { Neurons }\end{array}$ & $\begin{array}{c}\text { Double Labeled } \\
\text { NT Cells } \\
\begin{array}{c}\text { Total HRP-labeled } \\
\text { Cells/Nucleus }\end{array}\end{array} \times 100$ & $\begin{array}{c}\text { Number of Double } \\
\text { Labeled Serotonin } \\
\text { Neurons }\end{array}$ & $\begin{array}{c}\text { Double Labeled } \\
5 \text {-HT Cells } \\
\frac{\text { Total HRP-labeled }}{\text { Cells/Nucleus }}\end{array} \times 100$ \\
\hline & & $\%$ & & $\%$ \\
\hline Periaqueductal gray & ++++ & 31.9 & + & 9.4 \\
\hline B-9 group" & 0 & 0 & ++++ & 55.1 \\
\hline Cuneiformis & ++ & 12.8 & + & 2.7 \\
\hline B-8 group & 0 & 0 & +++ & 63.2 \\
\hline Solitarius & +++ & 35.7 & 0 & 0 \\
\hline Gigantocellularis pars $\alpha$ & 0 & 0 & ++ & 35.4 \\
\hline 1)orsal parabrachial & ++ & 17.6 & 0 & 0 \\
\hline Paragigantocellularis & + & 11.1 & ++ & 23.3 \\
\hline Ventral parabrachial & + & 13.2 & 0 & 0 \\
\hline $\begin{array}{l}\text { Area between lateral re- } \\
\text { ticular nucleus and } \\
\text { spinal trigeminal nu- } \\
\text { cleus }\end{array}$ & + & 16.6 & 0 & 0 \\
\hline Ventral spinal trigeminal & + & 44.4 & 0 & 0 \\
\hline A-5 group" & + & 11.2 & 0 & 0 \\
\hline
\end{tabular}

"Terminology of Dahlstrom and Fuxe (1964).

cleus. Each structure listed in Table I was found to contain NT double labeled cells in at least three experiments. The following commentary supplies supplementary information on the distribution of NT double labeled cells in selected areas.

At midbrain and isthmus levels, the largest number of NT double labeled cells were observed in the PAG. Two distinct patches of labeling were present within the PAG. One group of NT double labeled neurons was present in the ventrolateral quadrant of the PAG. The other group of labeled cells occurred in the dorsal PAG subdivision where they were most prominent at superior collicular levels (Fig. 4). Double labeled neurons in the ventrolateral PAG were predominantly small bipolar (12- to 18 $\mu \mathrm{m}$; Fig. 5), large fusiform (18- to $26-\mu \mathrm{m}$ ), and large triangular (18- to $25-\mu \mathrm{m})$ cells. Labeling in dorsal PAG neurons, however, occurred in small multipolar cells (14 to $20 \mu \mathrm{m}$ ) and small bipolar cells (12 to $18 \mu \mathrm{m}$ ). Double labeled NT neurons also were present in the nucleus cuneiformis and in the lateral wings of the dorsal raphe nucleus. Labeled neurons within the cuneiform nucleus were confined to its medial portion and were especially prominent at caudal levels. The cells which contained double label within the cuneiform nucleus were typically large multipolar neurons (28 to $42 \mu \mathrm{m}$ ) and triangular neurons ( 18 to $32 \mu \mathrm{m}$ ). Within the dorsal raphe nucleus, fusiform and polygonal double labeled cells were observed. However, control injections of HRP into the region immediately dorsal to the NRM indicated that much of the label within the dorsal raphe nucleus was due to the spread of the HRP from the NRM to the region dorsal to it. Finally, double labeled cells were found in the dorsal and ventral parabrachial nuclei at isthmus levels. Labeling occurred along the lateral aspect of the former nucleus but was more medially placed in the latter nucleus (Fig. 4).
At pontine levels, double labeled cells were observed in an area which corresponds to the A-5 region of Dahlstrom and Fuxe (1964). Labeled cells were also evident along the lateral aspect of the locus coeruleus. However, a comparison of control injections of HRP into the NRG with iontophoretic injections into the NRM suggests that the labeling within the locus coeruleus may be due to the spread of the enzyme from the NRM into the adjacent gigantocellular nucleus.

At medullary levels, double labeled neurons were present in the nucleus solitarius, the ventral reticular nucleus, the nucleus paragigantocellularis, the area between the lateral reticular nucleus (LRN) and the spinal trigeminal nucleus, and within the ventral portion of the spinal trigeminal nucleus. Cells which displayed both NT-like immunoreactivity and HRP reaction product in the nucleus solitarius were predominantly round to ovoid multipolar neurons (13 to $20 \mu \mathrm{m}$ ) and were localized to the caudal and lateral aspects of the nucleus (Fig. 4). The paragigantocellular nucleus displayed a few NT-HRP neurons within the lateral portion of the nucleus. These cells were typically ovoid multipolar neurons (16 to 24 $\mu \mathrm{m})$ or elongated fusiform-shaped cells. Finally, the labeled cells located in the region between the LRN and the spinal trigeminal nucleus appeared to lie in an area corresponding to the A-1 region of Dahlstrom and Fuxe (1964).

\section{Control injections}

A comparison of HRP labeling in the brain stem after iontophoretic injections of the enzyme into the raphe magnus, with labeling following injections into the adjacent reticular formation or the inferior olive, revealed some similarities and, more importantly, some major differences. Injections involving the inferior olivary com- 


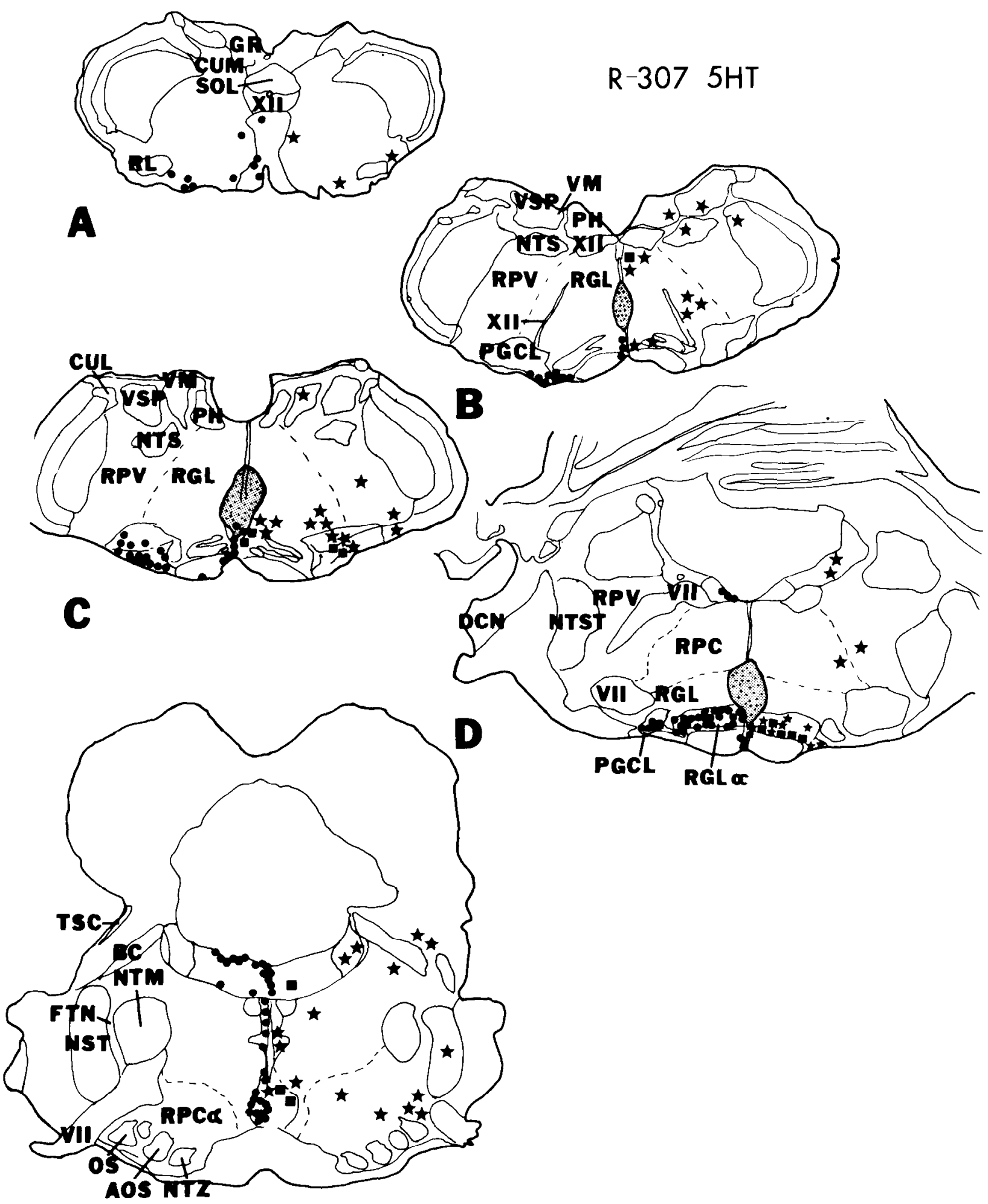

E

Figure $3 .^{3}$ A charting diagram depicting the distribution of serotonin-like immunoreactive neurons (solid circles) on the left side of the brain stem, sections $A$ to $I$. The locations of HRP single labeled neurons (stars) and double labeled serotonin-like immunoreactive cells (squares) are illustrated on the right side of the brain sections. The HRP injection site (stippled areas) is indicated in sections $B, C$, and $D$. 


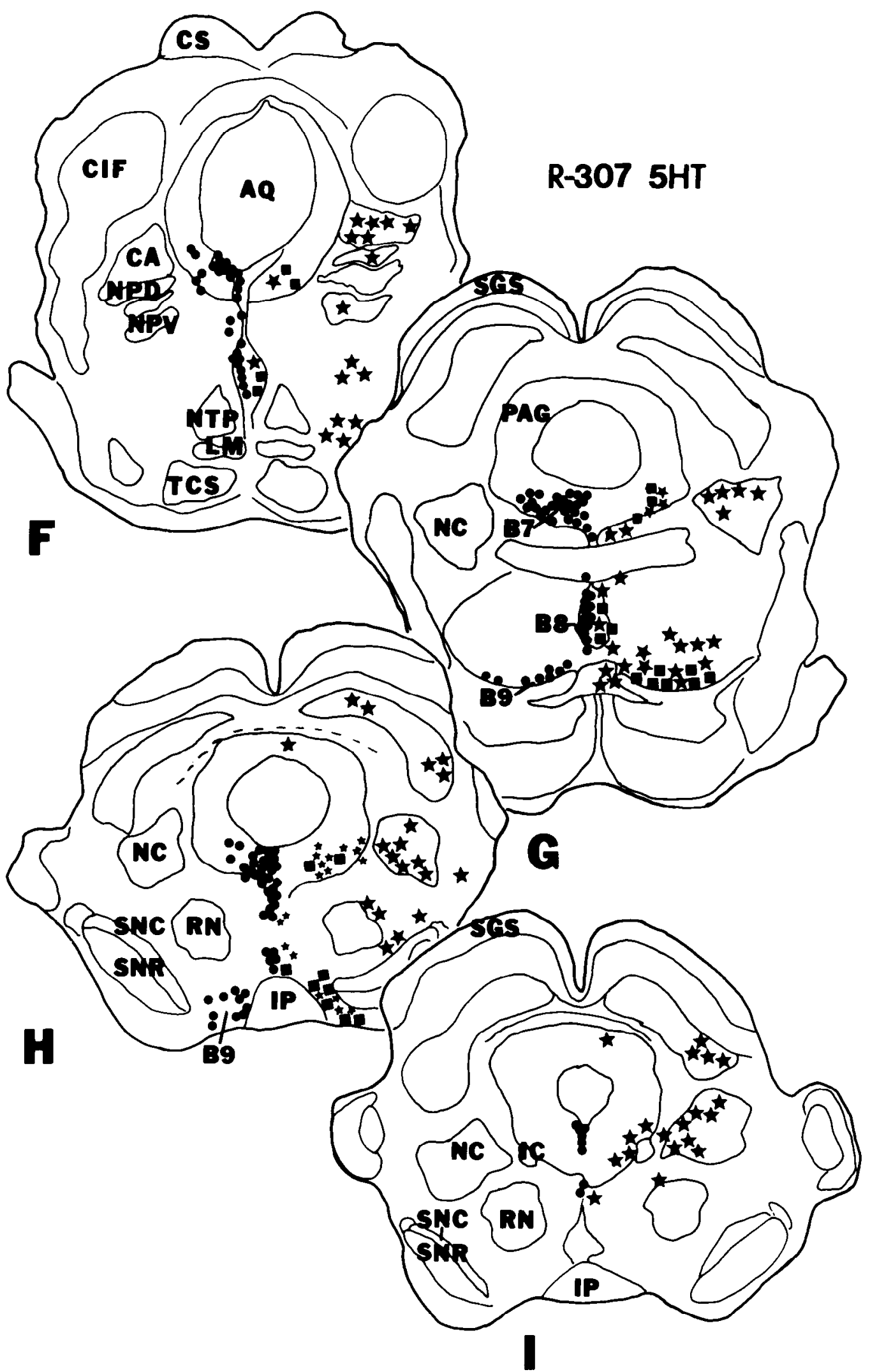

Figure 3. Continued.

nucleus; FTN, fibers of the trigeminal nerve; GR, nucleus gracilis; IC, interstitial nucleus of Cajal; III, cranial nerve; IO, inferior olive; IP, interpeduncular nucleus; llD, dorsal nucleus of the lateral lemniscus; IIV, ventral nucleus of the lateral lemniscus; LM, medial lemniscus; MG, medial geniculate body; NC, nucleus cuneiformis; ND, nucleus of
Darkschewitz; NPD, dorsal parabrachial nucleus; NPV, ventral parabrachial nucleus; NST, nucleus of the solitary tract; NTM, motor trigeminal nucleus; NTP, pontine tegmental nucleus; NTS, nucleus tractus solitarius; NTST, spinal nucleus of the trigeminal nerve; NTZ, nucleus of the trapezoid body; OS, superior olivary nucleus; PAG, 


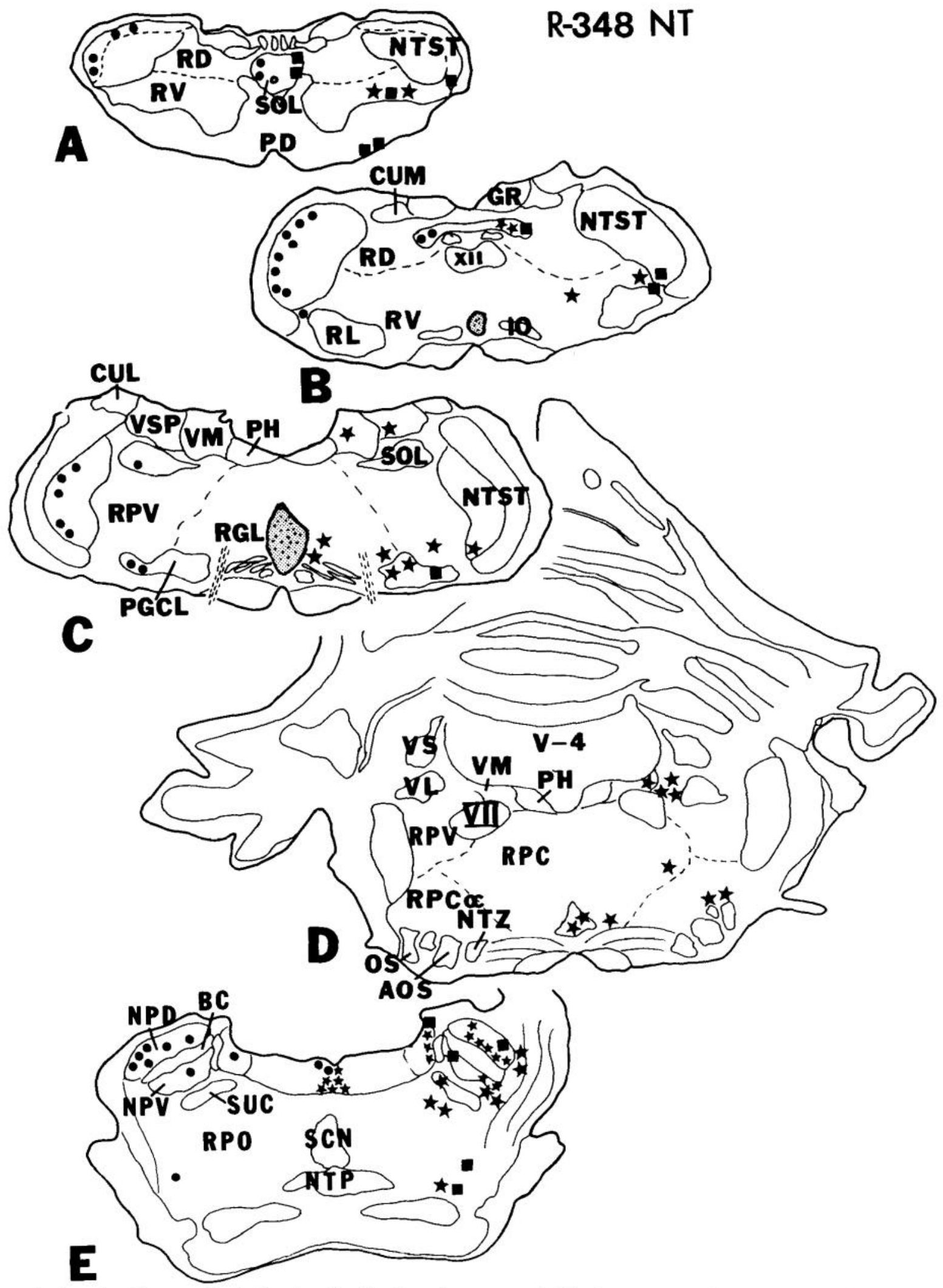

Figure 4. A charting diagram depicting the distribution of neurotensin-like immunoreactive neurons (solid circles) on the left side of the brain stem, sections $A$ to $I$. The locations of HRP single labeled neurons (stars) and double labeled neurotensin-like immunoreactive cells (squares) are illustrated on the right side of the brain sections. The HRP injection site (stippled areas) is indicated in sections $B$ and $C$.

periaqueductal gray; PD, pyramidal decussation; PGCL, paragigantocellular reticular nucleus; $\mathrm{PH}$, nucleus prepositus hypoglossi; $\mathrm{RD}$, dorsal reticular nucleus of the medulla; RGL, gigantocellular reticular nucleus;
RGL $\alpha$, gigantocellular reticular nucleus pars $\alpha$; RL, lateral reticular nucleus; RN, red nucleus; RPC, caudal pontine reticular nucleus; $\mathrm{RPC} \alpha$, caudal pontine reticular nucleus pars $\alpha$; RPO, rostral pontine reticular 


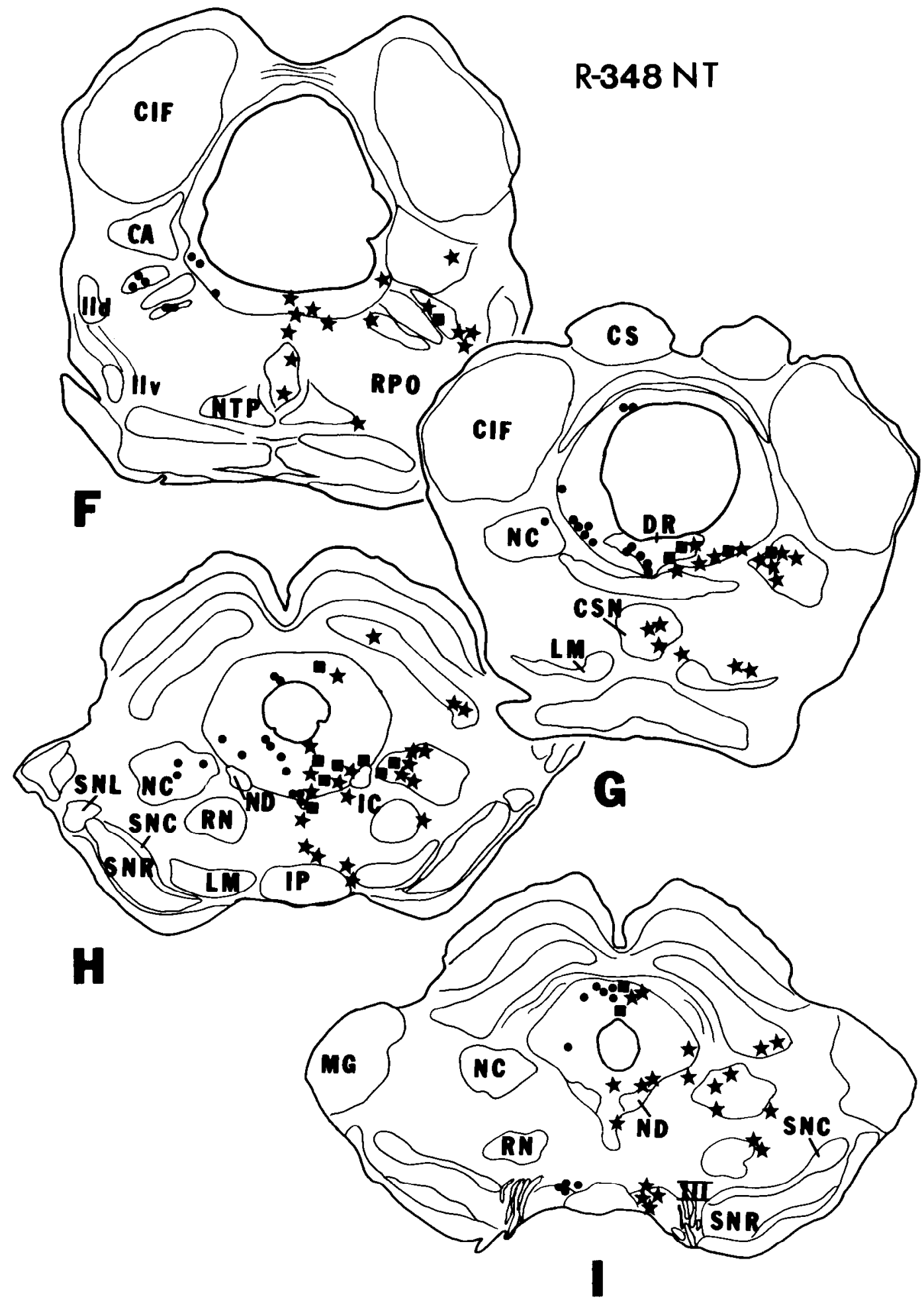

Figure 4. Continued.

plex, for instance, labeled neurons in the red nucleus, the nucleus of Cajal, the cerebellar nuclei, and the dorsal column nuclei. These nuclei were never labeled following HRP deposits confined to the NRM. However, both the
NRM and inferior olive were found to receive input from the periaqueductal gray, the zona incerta, and the vestibular complex. Involvement of the inferior olive occurred in three cases in the present study (R-265, R-289, and R- nucleus (pontis oralis); RPV, parvocellular reticular nucleus; $R V$, ventral reticular nucleus of the medulla; $\mathrm{SCN}$, superior central nucleus; SGS, stratum griseum superficiale; SNC, substantia nigra pars compacta; SNL, substantia nigra pars lateralis; SNR, substantia nigra pars reticulata; SOL, nucleus solitarius; SUC, nucleus subcoeruleus; TCS, corticospinal tract; TSC, spinocerebellar tract; V-4, fourth ventricle; VII, facial nerve; VL, lateral vestibular nucleus; VM, medial vestibular nucleus; VS, superior vestibular nucleus; VSP, spinal vestibular nucleus; XII, hypoglossal nucleus. 
290). Labeling occurred in both the red nucleus and the cerebellar nuclei in these three cases, but no HRP-labeled cells were present in these regions in any of the remaining cases.

Control HRP injections into the nucleus reticularis gigantocellularis (NRG) indicated that, although overlap exists in the projections to the NRG and NRM, each nucleus appears to receive a particular set of afferents which is specific to that nucleus. For example, injections of HRP into the NRG labeled a significant number of cells in the medial cerebellar nucleus. No labeled cells were present in this cerebellar nucleus following injections into the raphe magnus. NRG injections resulted in distinct labeling in the locus coeruleus. Deposits of HRP in the NRM resulted in only a few (case R-178) or no labeled cells (case R-171) in this nucleus. These results suggest that the majority of double labeled neurons found in the locus coeruleus in the present investigation probably are due to the spread into and subsequent uptake of the enzyme tracer from the NRG. Similarly, control injections into the area immediately dorsal to the NRM produced substantial labeling in both medial and lateral portions of the dorsal raphe nucleus, while NRM deposits of HRP resulted in no labeling (case R-171) or a rather small number of HRP-positive neurons (case R-178) confined to the lateralmost portions of the dorsal raphe. These latter cells appeared contiguous with those labeled in the ventrolateral PAG.

\section{Discussion}

The present immunohistochemical-retrograde transport study provides new information on the origin of serotonin and neurotensin projections to the nucleus raphe magnus. Serotonin input to the NRM arises from the B-7, B-8, and B-9 groups of Dahlstrom and Fuxe (1964). However, only $63 \%$ of the HRP-labeled neurons in the region of the B-8 group and 55\% of the HRP cells in the B-9 region contained 5-HT (Table I). This implies that $37 \%$ of the neurons in the B- 8 and $45 \%$ of the cells in the B-9 regions which project to the NRM utilize a neurotransmitter other than $5-\mathrm{HT}$. The transmitter(s) which subserves this projection from the non-serotonergic neurons in the B-8 and B-9 region to the NRM requires further elucidation. Since the single labeled HRP cells in the rostral B-9 region also lie in the vicinity of the A-10 group of Dahlstrom and Fuxe, it is possible that some of these cells utilize dopamine as a neurotransmitter. Stimulation in the B-9 region has been shown to produce analgesia (Mayer et al., 1971) and it is feasible that the B-9 projection to the NRM may subserve stimulation-produced analgesia in this region. Similarly, the autoradiographic study of Bobillier and co-workers (1979) has shown direct projections from the B-8 region to the NRM and the stimulation-mapping investigation of Oliveras and collaborators (1979) has implicated this region in electrical analgesia.

Within the B-7 group, double labeled 5-HT cells were observed in the ventrolateral PAG and the lateral aspect of the dorsal raphe nucleus. Our control injections, however, indicated that labeling within the dorsal raphe was due to the spread of the HRP into the area immediately dorsal to the NRM. This is consistent with previous retrograde transport studies of afferent projections to the raphe magnus (Gallager and Pert, 1978; Abols and Bas-
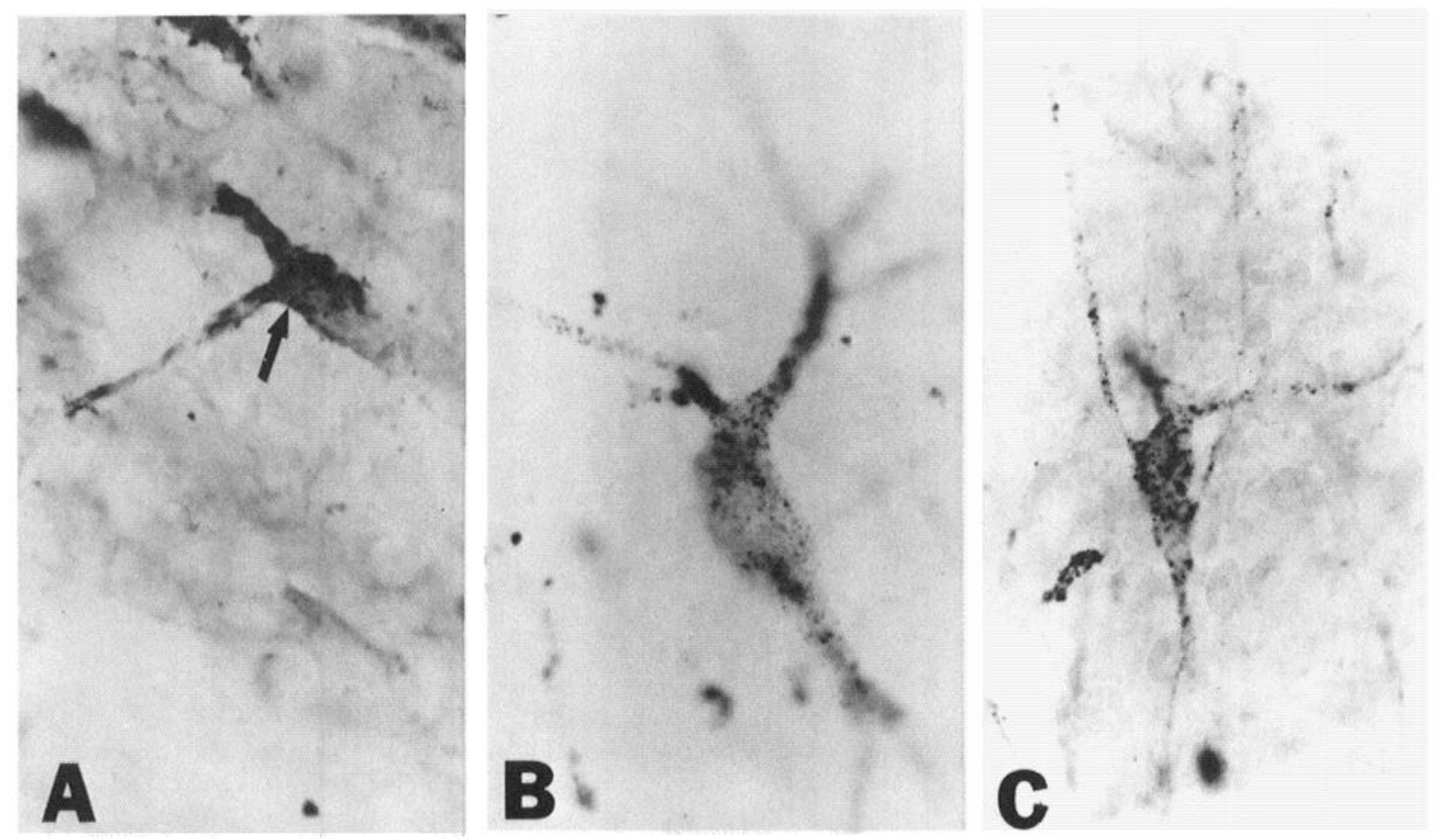

Figure 5. Three photomicrographs illustrating neurotensin-like immunoreactive neurons. $A$, Single labeled neurotensinimmunoreactive neuron (arrow) from the ventrolateral periaqueductal gray. Magnification $\times 500$. B, Double labeled neuron from the periaqueductal gray. Magnification $\times 700$. $C$, Double labeled neurotensin-like immunoreactive neuron from the dorsal parabrachial nucleus. Magnification $\times 425$. 
baum, 1981; Carlton et al., 1981). Within the ventrolateral PAG, $9.4 \%$ of the HRP-labeled cells contained 5-HT-like immunoreactivity. This finding is of interest in light of the fact that the majority of studies of 5-HT involvement in endogenous analgesia systems have focused on the serotonergic projections from medullary nuclei to the spinal cord (see Mayer, 1979). Thus, studies of serotonin involvement in central pain suppression which utilize intracisternal or intravenous infusion of 5-HT-blocking agents must take into account their effect on the PAGNRM pathway as well as their effect on the NRM-spinal pathway. The PAG-NRM pathway has been shown to be excitatory (Fields and Anderson, 1978; Lovick et al., 1978; Behbehani and Fields, 1979) and the present investigation indicates that part of this projection is mediated by $5-\mathrm{HT}$. This finding is supported by recent electrophysiological evidence (Yezierski et al., 1981). The present results, however, also suggest that about $90 \%$ of the PAG neurons which project to the NRM are non-serotonergic. A large component of this projection is apparently neurotensinergic (Table I). Although the PAG contains a large number of enkephalin and substance $P$ neurons (Hokfelt et al., 1977a, b) and some noradrenergic cells (Nowaczyk et al., 1978), these neurons do not appear to be involved in the PAG-NRM pathway (Prichard and Beitz, 1981; Behbehani et al., 1981). Identification of other neurotransmitters and neuropeptides which are involved in mediation of the interaction between the PAG and NRM requires further investigation.

The remaining two nuclei which furnish $5-\mathrm{HT}$ input to the NRM are the nucleus gigantocellularis pars $\alpha$ and the nucleus paragigantocellularis (PGCL). An excitatory 5HT projection from the PGCL to the NRM has been postulated by Couch (1976) and the present study provides support for this hypothesis. The PGCL also supplies NT fibers (Table I) and a major enkephalin projection (Prichard and Beitz, 1981) to the NRM. Recent studies in our laboratory indicate that PGCL metabolic activity increases dramatically during PAG stimulationinduced analgesia (Beitz and Buggy, 1981), further implicating this structure in central analgesic mechanisms. The precise interaction between the PGCL and NRM during opiate or stimulation-produced analgesia deserves electrophysiological analysis.

The present study confirms the report of Uhl and Snyder (1981) concerning the location of brain stem neurotensin-immunoreactive cells and supplies novel data on the organization of NT projections to the NRM. To my knowledge, there have been no anatomical or pharmacological investigations of neurotensin pathways to raphe nuclei, nor have any electrophysiological data been reported on the effect of NT on raphe magnus neurons. A review of the literature indicates that the predominant effect produced by iontophoretically applied neurotensin in the frontal cortex, hippocampus, striatum, and spinal cord dorsal horn is an increase in firing rate (Miletic and Randic, 1978; Zieglgansberger et al., 1978). In contrast, iontophoresis of NT into the locus coeruleus decreases the firing rate of these cells (ScottYoung et al., 1978). Since the PAG-NRM projection has been shown to be excitatory as indicated above, it might be anticipated that the NT projections to the NRM are excitatory. Several brain stem nuclei have been shown in the present study to provide NT projections to the NRM (Table I). Based on these findings and on the fact that intracisternally administered NT produces potent analgesia (Clineschmidt et al., 1979; Nemeroff et al., 1980), it is apparent that an electrophysiological analysis of the N'T input to the NRM would provide important information relevant to our understanding of endogenous analgesia mechanisms.

Finally, the demonstration of NT projections to the NRM from the region of the A-1 and A-5 cell groups of Dahlstom and Fuxe (1964) is of interest. Since only $16.6 \%$ of the HRP-labeled cells contained NT in the former nucleus and only $11.2 \%$ of the HRP cells were double labeled in the latter area, it is probable that some of the remaining single HRP-labeled cells in these two nuclei provide a noradrenergic (NA) input to the NRM. This is consistent both with the demonstration by Hammond and co-workers (1980) that microinjections of noradrenergic antagonists into the NRM produce hypoalgesia and with the suggestion by Levitt and Moore (1979) that NA input to the NRM may originate in areas A-1 and A5. The possibility of NT and noradrenalin coexisting in the same neurons in the $A-1$ and $A-5$ region deserves further study especially in light of the fact that noradrenalin produces inhibition of NRM neurons (Hammond et al., 1980).

The relationship of opiate receptor distribution to the location of NT and 5-HT cells which project to the $N R M$. Since the raphe magnus has been shown to have low levels of opiate binding sites (Atweh and Kuhar, $1977 \mathrm{a}, \mathrm{b})$, it is probable that opiate compounds act indirectly on NRM neurons through the activation of other regions which, in turn, influence the NRM (Anderson et al., 1977). Several nuclei, identified in the present study as sending NT projections to the NRM, have been shown to contain high amounts of opiate binding sites. These include the PAG, the ventral and dorsal parabrachial nuclei, and the nucleus solitarius (Atweh and Kuhar, 1977a, b; Herkenham and Pert, 1980). Coincidentally, the parabrachial nuclei and the nucleus solitarius display increased metabolic activity during PAG stimulationproduced analgesia (Beitz and Buggy, 1981). The nucleus cuneiformis and the A-1 region of Dahlstrom and Fuxe (1964) were found in the present analysis to send NT projections to the NRM. These areas also have been shown to contain a moderate amount of opiate binding sites (Atweh and Kuhar, 1977b; Pearson et al., 1980). Morphine and other opiate compounds thus may influence the NRM indirectly by acting on these nuclei.

Although very few opiate receptors appear to be present in the nucleus paragigantocellularis, Takagi (1980) has shown that direct injections of morphine or enkephalin into this region produce pronounced analgesia. Injections of morphine into the PGCL simultaneously with injections into PAG also have been shown to produce an analgesic effect significantly greater than the effect of either nucleus injected alone (Rosenfeld and Stocco, 1981). The present study has identified the PGCL as a source of both 5-HT and NT projections to the raphe magnus. Our results taken together with those of Takagi and Rosenfeld and Stocco suggest that this area also may be involved in the indirect effects of opiates on NRM neuronal activity. 
Technical problems and considerations. The use of the combined HRP retrograde transport-PAP immunohistochemical technique has several advantages over other double labeling methods. Foremost among these is the permanence of the preparation. Both the HRP and $P A P$ reaction products are rather stable and do not suffer from fading and quenching as fluorescent double labeling methods do. Furthermore, the black HRP granules contrast with the brown immunohistochemical reaction product, making identification of double labeled neurons easy and straightforward. Despite these obvious advantages, there are a number of problems inherent in the technique which must be considered. The first of these is the insensitivity of the cobalt chloride-DAB procedure for detecting HRP labeling. An evaluation of the sensitivity of nine HRP histochemical methods has indicated that the DAB-cobalt chloride procedure ranks about seventh in sensitivity (Mesulam and Rosene, 1979). In two of our cases, we reacted alternate sections with the cobalt chloride-DAB method and the TMB method, respectively. The TMB method resulted in substantially more labeling within brain stem nuclei than the cobalt chloride-DAB procedure, thus supporting the results of Mesulam and Rosene. The second factor contributing to the insensitivity of the method is the fixation procedure. In order to preserve antigen-antibody reactivity for the immunohistochemical phase of the double labeling, a $4 \%$ paraformaldehyde fixative is used. It has been shown, however, that glutaraldehyde fixation is the method of choice in order to obtain ideal HRP reactivity in retrogradely labeled cells (Rosene and Mesulam, 1978). In an attempt to maintain some of the benefits of glutaraldehyde fixation, we have begun to add small amounts of glutaraldehyde to our $3.5 \%$ paraformaldehyde fix. Glutaraldehyde in amounts ranging from 0.1 to $0.5 \%$ can be added to the fixation solution without seriously affecting immunoreactivity. The addition of glutaraldehyde, moreover, appears to enhance the HRP retrograde labeling.

The final and most serious factor affecting the HRP retrograde transport-immunohistochemical method is the use of colchicine to enhance neuronal immunoreactivity. Colchicine is employed to inhibit axonal transport and thus allow neuropeptide concentrations to increase within the neuronal cell body (Hokfelt et al., 1977a). Once the cell body concentrations of a particular neuropeptide have increased, the cells are more readily identified immunohistochemically with antisera to the neuropeptide. However, since colchicine interferes with axonal transport, it also blocks the retrograde transport of HRP. It has been our experience that, if an HRP-injected animal is perfused $48 \mathrm{hr}$ or more after colchicine administration, the number of HRP-positive neurons found within the brain stem is substantially reduced and, in some cases, no retrogradely labeled cells can be identified. In order to maximize the number of HRP-labeled neurons and, at the same time, identify neuropeptidecontaining cell bodies immunohistochemically, animals are routinely perfused in our laboratory 20 to $24 \mathrm{hr}$ after colchicine administration.

In their initial paper detailing the combined retrograde HRP-immunohistochemical technique, Bowker and coworkers (1981) indicate that they injected 1 to $4 \mu$ l of a 25 to $50 \%$ solution of HRP into the rodent spinal cord.
The large quantity of HRP injected into the spinal cord in their cases may have compensated to a large extent for the problems of fixation, utilization of colchicine, and use of an inferior method for detection of the HRP. In studies of small brain stem nuclei, the utilization of large quantities of HRP is impractical due to the large amount of spread of the tracer enzyme. In addition, the problems inherent in the HRP double labeling method limit the use of extremely small injections of the tracer. In the present study, both iontophoretic injections and pressure injections of less than $0.1 \mu \mathrm{l}$ of HRP were found to result in very little labeling throughout the brain stem. This minimal labeling can be attributed predominantly to a combination of the use of colchicine and the cobalt chloride-DAB procedure due to the fact that iontophoretic injections resulted in numerous HRP-marked cells in animals which were fixed with $3.5 \%$ paraformaldehyde, $0.2 \%$ glutaraldehyde and were not injected with colchicine and whose tissue was processed with the TMB procedure. All of these factors must be considered when the retrograde $\mathrm{HRP}$-immunohistochemical procedure is utilized.

Finally, the problem of the spread of HRP from the injection site to surrounding nuclci and subsequent direct uptake of the enzyme by neurons within these nuclei will be discussed. Because of the close proximity of some nuclear groups, especially the PGCL, to the raphe magnus and the relatively large injection volume of HRP used in the present study $(0.2 \mu \mathrm{l}$ of HRP were injected in over half of the cases), the possibility of direct uptake of HRP rather than retrograde transport of the enzyme must be considered. Projections from the PGCL to the NRM have been demonstrated previously with both anterograde and retrograde transport techniques. Abols and Basbaum (1981) have described HRP-labeled neurons within the feline nucleus paragigantocellularis following small iontophoretic injections of the tracer into the NRM. Similarly, HRP-labeled cells were found in the PGCL in the present investigation following iontophoretic delivery of the enzyme into the raphe magnus. Using the anterograde autoradiographic technique, Loewy and collaborators (1981) also have demonstrated PGCL projections to the NRM. Since there is strong evidence for the existence of a PGCL-NRM pathway and since the results shown in Table I were taken from cases in which there was no apparent spread of the HRP injection site into the PGCI, it is probable that the majority of double labeled neurons observed within this nucleus represents true retrograde transport of the enzyme marker. However, the possibility of some false HRP labeling due to direct uptake of HRP by dendrites of PGCL neurons which extend outside of the nucleus cannot be ruled out.

In summary, the present study demonstrates the cells of origin of brain stem neurotensin and serotonin projections to the nucleus raphe magnus. The largest 5-HT inputs to the NRM arise from the B-8 and B-9 groups of Dahlstrom and Fuxe (1964) and from the PGCL. The majority of the NT projections to the NRM arise from the PAG, the nucleus solitarius, and the dorsal parabrachial nuclei. The periaqueductal gray and the nucleus reticularis paragigantocellularis were found to provide both 5-HT and NT projections to the NRM. These 
regions have been implicated in central analgesic mechanisms (Fields and Basbaum, 1978) and it is probable that both 5-H'T and NT may be involved in PAG and PGCL influences on NRM.

\section{References}

Abols, I. A., and A. I. Basbaum (1981) Afferent connections of the rostral medulla of the cat: A neural substrate for midbrain-medullary interactions in the modulation of pain. J. Comp. Neurol. 201: 285-297.

Adams, J. C. (1981) Heavy metal intensification of DAB-based HRP reaction product. J. Histochem. Cytochem. 29: 775.

Anderson, S. D., A. I. Basbaum, and H. L. Fields (1977) Response of medullary raphe neurons to peripheral stimulation and to systemic opiates. Brain Res. 123: 363-368.

Atweh, S. F., and M. J. Kuhar (1977a) Autoradiographic localization of opiate receptors in rat brain. I. Spinal cord and medulla. Brain Res. 124: 53-67.

Atweh, S. F., and M. J. Kuhar (1977b) Autoradiographic localization of opiate receptors in rat brain. II. The brain stem. Brain Res. 129: 1-12.

Basbaum, A. I., N. J. E. Marley, J. O'Keefe, and C. H. Clanton (1977) Reversal of morphine and stimulus-produced analgesia by subtotal spinal cord lesions. Pain 3: 43-56.

Behbehani, M. M., and H. L. Fields (1979) Evidence that an excitatory connection between the periaqueductal gray and nucleus raphe magnus mediates stimulation produced analgesia. Brain Res. 170: 85-93.

Behbehani, M. M., S. L. Pomeroy, and C. E. Mack (1981) Interaction between central gray and nucleus raphe magnus: Role of norepinephrine. Brain Res. Bull. 6: 361-364.

Beitz, A. J. (1982) The organization of afferent projections to the midbrain periaqueductal gray of the rat. Neuroscience 7 : $133-159$

Beitz, A. J., and J. Buggy (1981) Brain functional activity during PAG stimulation-produced analgesia: A 2-DG study. Brain Res. Bull. 6: 487-494.

Bobillier, P., S. Seguin, A. Dequeurce, B. D. Lewis, and J. F. Pujol (1979) The efferent connections of the nucleus raphe centralis superior in the rat as revealed by radioautography. Brain Res. 166: 1-8.

Bowker, R. M., H. W. M. Steinbusch, and J. D. Coulter (1981) Serotonergic and peptidergic projections to the spinal cord demonstrated by a combined retrograde HRP histochemical and immunocytochemical staining method. Brain Res. 211: 412-418.

Carlton, S. M., E. G. Young, G. R. Leichnetz, and D. J. Mayer (1981) Nucleus raphe magnus afferents in the rat: A retrograde study using horseradish peroxidase gel implants and tetramethylbenzidine neurohistochemistry. Soc. Neurosci. Abstr. 7: 229.

Clineschmidt, B. V., J. C. McGuffin, and P. B. Bunting (1979) Neurotensin: Antinociceptive action in rodents. Eur. J. Pharmacol. 54: 129-139.

Couch, J. R. (1976) Further evidence for a possible excitatory serotonergic synapse on raphe neurons of pons and lower midbrain. Life Sci. 19: 761-768.

Dahlstrom, A., and K. Fuxe (1964) Evidence for the existence of monoamine containing neurons in the central nervous system. I. Demonstration of monamines in the cell bodies of brain stem neurons. Acta Physiol. Scand. Suppl. 232 62: 155.

Deakin, J. F. W., A. H. Dickson, and J. O. Dostrovsky (1977) Morphine effects on rat raphe magnus neurons. J. Physiol. (Lond.) 267: 46-47P.

Dickenson, A. H., .J. I. Oliveras, and J. M. Besson (1979) Role of the nucleus raphe magnus in opiate analgesia as studied by the microinjection technique in the rat. Brain Res. 170: 95-112.
Fields, H. L., and S. D. Anderson (1978) Evidence that raphespinal neurons mediate opiate and midbrain stimulation-produced analgesias. Pain 5: 333-349.

Fields, H. L., and A. I. Basbaum (1978) Brainstem control of spinal pain transmission neurons. Annu. Rev. Physiol. 40: 193-221.

Gallager, D. W., and A. Pert (1978) Afferents to brain-stem nuclei (brain stem raphe, nucleus reticularis pontis caudalis and nucleus gigantocellularis) in the rat as demonstrated by microiontophoretically applied HRP. Brain Res. 144: 257276.

Hammond, D. L., R. A. Levy, and H. K. Proudfit (1980) Hypoalgesia following microinjection of noradrenergic antagonists in the nucleus raphe magnus. Pain 9: 85-101.

Herkenham, M., and C. B. Pert (1980) In vitro autoradiography of opiate receptors in rat brain suggests loci of "opiatergic" pathways. Proc. Natl. Acad. Sci. U. S. A. 77: 5532-5536.

Hokfelt, R., R. Elde, O. Johansson, L. Terenius, and L. Stein (1977a) The distribution of enkephalin-immunoreactive cell bodies in the rat central nervous system. Neurosci. Lett. 5 : 25-31.

Hokfelt, T., A. Ljungdahl, L. Terenius, R. Elde, and G. Nilsson (1977b) Immunohistochemical analysis of peptide pathways possibly related to pain and analgesia: Enkephalin and substance P. Proc. Natl. Acad. Sci. U. S. A. 74: 3081-3085.

Levitt, P., and R. Y. Moore (1979) Origin and organization of brainstem catecholamine innervation in the rat. J. Comp. Neurol. 186: 505-528.

Loewy, A. D., J. H. Wallach, and S. MeKellar (1981) Efferent connections of the ventral medulla oblongata in the rat. Brain Res. Rev. 3: 63-80.

Lovick, T. A., D. C. West, and J. H. Wolstencroft (1978) Responses of raphe spinal and other bulbar raphe neurones to stimulation of the periaqueductal gray in the cat. Neurosci. Lett. 8: 45-49.

Maley, B., and R. P. Elde (1982) Immunohistochemical localization of putative neurotransmitters within the feline nucleus tractus solitarius. Neuroscience, in press.

Mayer, D. .J. (1979) Endogenous analgesia systems: Neural and behavioral mechanisms. In Advances in Pain Research and Therapy, J. J. Bonica, ed., Vol. 3, pp. 395-410, Raven Press, New York.

Mayer, D. J., and J. C. Liebeskind (1974) Pain reduction by focal electrical stimulation of the brain: An anatomical and behavioral analysis. Brain Res. 68: 73-93.

Mayer, D. J., T. L. Wolfe, H. Akil, B. Carder, and J. C. Liebeskind (1971) Analgesia from electrical stimulation in the brain stem of the rat. Science 174: 1351-1354.

Mesulam, M. M., and D. L. Rosene (1979) Sensitivity in horseradish peroxidase neurohistochemistry: A comparative and quantitative study of nine methods. J. Histochem. Cytochem. 27: 763-773.

Miletic, V., and M. Randic (1978) Excitatory action of neurotensin on cat dorsal horn neurones in laminae I-III. In Abstracts, 7th International Congress of Pharmacology, p. 472, Pergamon Press, Elmsford, NY.

Nemeroff, C. B., D. Luttinger, and A. J. Prange, Jr. (1980) Neurotensin: Central nervous system effects of a neuropeptide. Trends Neurosci. 3: 1-4.

Nowaczyk, 'T., J. F. Pujol, J. L. Valatx, and P. Bobiller (1978) Differential radioautographic visualization of central catecholaminergic neurons following intracisternal or intraventricular injection of tritiated norepinephrine. Brain Res. 152: $567-572$

Oleson, T. D., D. A. Twombly, and J. C. Liebeskind (1978) Effects of pain attenuating brain stimulation and morphine on electrical activity in the raphe nuclei of the awake rat. Pain 4: 211-230.

Oliveras, J. L., G. Guilbaud, and J. M. Besson (1979) A map of serotoninergic structures involved in stimulation producing 
analgesia in unrestrained freely moving cats. Brain Res. 164: 317-322.

Pearson, J., L. Brandeis, E. Simon, and J. Hiller (1980) Radioautography of binding of tritiated diprenorphine to opiate receptors in the rat. Life Sci. 26: 1047-1052.

Pomeroy, S. L., and M. M. Behbehani (1979) Physiological evidence for a projection from periaqueductal gray to nucleus raphe magnus in the rat. Brain Res. 176: 143-147.

Prichard, S. M., and A. J. Beitz (1981) The localization of brain stem enkephalinergic and substance-P neurons which project to the rodent nucleus raphe magnus. Soc. Neurosci. A bstr. 7: 59.

Proudfit, H. K. (1981) Time-course of alterations in morphineinduced analgesia and nociceptive threshold following medullary raphe lesions. Neuroscience 6: 945-951.

Reynolds, D. V. (1969) Surgery in the rat during electrical analgesia induced by focal brain stimulation. Science 164: 444-445.

Rosene, D. L., and M. M. Mesulam (1978) Fixation variables in horseradish peroxidase neurohistochemistry. I. The effects of fixation time and perfusion procedures upon enzymatic activity. J. Histochem. Cytochem. 26: 28-39.

Rosenfeld, J. P., and S. Stocco (1981) Effects of midbrain, bulbar and combined morphine microinjections and systemic injections on orofacial nociception and rostral trigeminal stimulation: Independent midbrain and bulbar opiate analgesia systems? Brain Res. 215: 342-348.
Ruda, M. T. (1976) Autoradiographic study of the efferent projections of the midbrain central gray in the cat. Doctoral thesis, University of Pennsylvania.

Scott-Young, W., G. R. Uhl, and M. J. Kuhar (1978) Iontophoresis of neurotensin in the area of the locus coeruleus. Brain Res. 150: 431-435.

Sternberger, L. A. (1979) The unlabeled antibody peroxidaseantiperoxidase (PAP) method. In Immunocytochemistry, L. Sternberger, ed., pp 104-169, John Wiley and Sons, New York.

Takagi, H. (1980) The nucleus reticularis paragigantocellularis as a site of analgesic action of morphine and enkephalin. Trends Pharmacol. Sci. 1: 182-184.

Uhl, G. R., and S. H. Snyder (1981) Neurotensin. In Neurosecretion and Brain Peptides, J. B. Martin, S. Reichlin, and K. L. Bick, eds., pp. 87-106, Raven Press, New York.

Yezierski, R. P., T. K. Wilcox, and W. D. Willis (1981) The effects of serotonin antagonists on the inhibition of primate spinal tract cells produced by stimulation in nucleus raphe magnus or periaqueductal gray. J. Pharmacol. Exp. Ther. 220: $266-277$.

Zieglgansberger, W., G. B. Siggins, M. Brown, W. Vale, and F. E. Bloom (1978) Actions of neurotensin upon single neurone activity in different brain regions of the rat brain. In $A b$ stracts, 7th International Congress of Pharmacology, p. 126, Pergamon Press, Elmsford, NY. 